\title{
The acute effects of coffee on glucose metabolism
}

\author{
T. M. Robertson ${ }^{1}$, M. N. Clifford ${ }^{1}$, S. Penson ${ }^{2}$, G. Chope ${ }^{2}$ and M. D. Robertson ${ }^{1}$ \\ ${ }^{1}$ University of Surrey, Guildford, GU2 $7 X H$ and ${ }^{2}$ Campden BRI, Chipping Campden, GL55 6LD
}

This abstract was awarded the student prize for best original Oral Communication.

Epidemiological studies suggest that people who drink coffee are less likely to develop Type 2 Diabetes ${ }^{(1)}$, however acute intervention studies often show that coffee has a potentially detrimental effect on glucose metabolism by increasing the postprandial glucose response $^{(2)}$. Previous acute studies have used a single large dose of coffee, typically containing the caffeine equivalent of $2-4$ mugs of coffee. It is unknown whether the acute effects of coffee are dose dependent or whether a "normal" dose of coffee will disrupt glucose metabolism.

This study investigated whether coffee affects glucose metabolism in a dose-dependent fashion, starting from one mug of coffee. It further looked to separate out the effects of caffeine (CF) from other coffee components by varying the doses of each independently, as it has been suggested that whilst caffeine may increase postprandial glucose, other coffee components may counteract this ${ }^{(3)}$.

Ten healthy overweight males participated in a two part randomised double blind crossover study. In the first part they ingested decaffeinated coffee (DC, 2, 4 or $8 \mathrm{~g}$ instant dissolved in $400 \mathrm{ml}$ water) with CF added in proportion to DC (total 100 , 200 or $400 \mathrm{mg} \mathrm{CF}$ ) or placebo ( $400 \mathrm{ml}$ water) along with $50 \mathrm{~g}$ glucose. In the second part they ingested the same amounts of DC (2, 4, $8 \mathrm{~g}$ ) or placebo, but with a standard $100 \mathrm{mg} \mathrm{CF}$ in each. Capillary blood samples were taken every $15 \mathrm{~min}$ for $2 \mathrm{hr}$ after each drink and glucose and insulin measured.

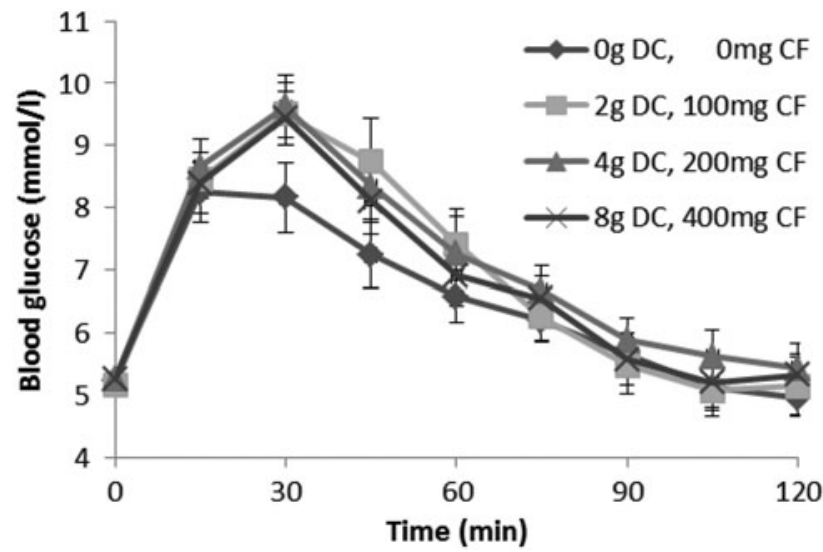

Fig. 1. Postprandial glucose response when caffeine was varied in line with coffee.

Repeated measures ANOVA on postprandial glucose found a treatment effect when CF was varied in line with DC $(p<0 \cdot 01$, Fig. 1). Post hoc analysis revealed both $2 \mathrm{~g}(p<0.05)$ and $4 \mathrm{~g}(p<0.05) \mathrm{DC}(100 \mathrm{mg}$ and $200 \mathrm{mg} \mathrm{CF}$, respectively) increased the glycaemic response versus placebo. There was no difference in glucose between treatments when caffeine remained constant at $100 \mathrm{mg}$.

These results demonstrate that one standard mug of coffee $(2 \mathrm{~g})$ is sufficient to disrupt glucose metabolism. Furthermore, the amount of caffeine found in one mug $(100 \mathrm{mg})$ is sufficient to mask any potential beneficial effects of other components. No dosedependent effect was found. Postprandial insulin was not affected by any coffee/caffeine combination.

1. Ding M, Bhupathiraju SN, Chen M et al. (2014) Caffeinated and decaffeinated coffee consumption and risk of type 2 diabetes: a systematic review and a dose-response meta-analysis. Diabetes care. 37(2), 569-86.

2. Moisey LL, Kacker S, Bickerton AC et al. (2008) Caffeinated coffee consumption impairs blood glucose homeostasis in response to high and low glycemic index meals in healthy men. Am J Clin Nutr. 87(5), 1254-61.

3. Johnston KL, Clifford MN, Morgan LM. (2003) Coffee acutely modifies gastrointestinal hormone secretion and glucose tolerance in humans: glycemic effects of chlorogenic acid and caffeine. Am J Clin Nutr. 78(4), 728-33. 